\title{
Preventing violence against women: time to uphold an important aspect of the reproductive health needs of women in Nigeria
}

\author{
Perpetus Chudi Ibekwe
}

\section{Background}

Violence against women (VAW) is one area of reproductive health that has not been given due consideration in Nigeria despite the fact that Nigeria is a signatory to many international conventions on eliminating violence against women and promoting human rights. ${ }^{1,2}$ VAW is increasingly being recognised as a serious public health issue, resulting in significant physical, psychological and social impairment. ${ }^{3}$ The World Health Organization, nongovernmental organisations and other agencies have recognised this and called on countries to take appropriate measures to prevent violence against women.., 5 The 1994 International Conference on Population and Development Programme of Action is very specific about sexual violence when it states: "Countries should take full measures to eliminate all forms of exploitation, abuse, harassment and violence against women, adolescents and children". 6 Also, one of the key issues addressed at the Fourth World Conference on Women in Beijing in 1995 was the elimination of violence against women. ${ }^{7}$

Several years after these conferences and conventions, which Nigeria ratified, violence against women still affects the lives of millions of women worldwide and cuts across ethnic, cultural and religious barriers, impinging on the rights of women to participate fully in society. ${ }^{8}$ In Nigeria, there is gross underreporting of VAW but available data indicate that $24-79 \%$ of women have experienced physical assault by an intimate partner. ${ }^{2,9-12}$ Unfortunately, this is tolerated as a cultural norm and accepted more or less as part of the rules guiding intimate relationships, as entrenched in parts of the penal code operating in some states in Nigeria.

\section{Consequences of VAW}

The health and psychosocial consequences of VAW are enormous. Victims of domestic violence are at a higher risk of several common gynaecological disorders and complications in pregnancy, where the health and safety of two potential victims are placed in danger. ${ }^{13}$ It has been shown that children who witness violence between their parents are at increased risk of childhood behavioural problems and of violence in future relationships. ${ }^{14}$ Abused women are more likely to suffer psychological distress in addition to engaging in harmful practices such as substance and alcohol abuse. ${ }^{2}$

Cross-sectional studies show that $40 \%$ of women in South Africa reported that their first sexual intercourse was forced. ${ }^{15}$ Schoepf ${ }^{16}$ has suggested that in Eastern and Central Africa, as a result of the targeting of younger females for sex (owing largely to the belief that "they have not been contaminated"), girls' first sexual experience may involve violence and force with older persons. In Nigeria,

J Fam Plann Reprod Health Care 2007; 33(4): 235-236

Department of Obstetrics and Gynaecology, Ebonyi State University Teaching Hospital, Abakaliki, Nigeria

Perpetus Chudi Ibekwe, MBBS, FWACS, Consultant

Correspondence to: Dr P C Ibekwe, PO Box 1019, Abakaliki 4800001, Nigeria. E-mail: drogoperps@yahoo.com
$12.4 \%$ of girls had experienced sexual intercourse before the age of 11 years. ${ }^{17}$ Ejikeme, ${ }^{18}$ in his review, asserted that such sexual experiences are as traumatic as they are destabilising, and he established a relationship between these practices and adolescent suicide, loss of self-worth and poor mental health.

\section{Harmful cultural practices}

It is estimated that about 100 million women and girls in Africa have undergone some form of genital mutilation, 19 whereas in Nigeria, an estimated $60 \%$ of women are genitally mutilated in one form or another. ${ }^{20}$

Ibekwe 21 highlighted the physical and psychological sequelae associated with female genital mutilation. Other harmful traditional practices that are detrimental to women's health and rights include widowhood practices, wife inheritance, denial of access to education, trafficking in women and girls, and economic discrimination. Widowhood practice is an offensive and dehumanising traditional practice, which varies with culture and ethnic group. It includes sleeping on a bare floor, drinking the deceased's bathwater, eating from broken plates and staying indoors for 1 year. Interwoven with the widowhood practice is wife inheritance, in which a woman is handed over to her deceased husband's relation, often against her wishes. When a woman loses her husband, she is automatically willed to a junior brother or another relation of the deceased husband, with all the attendant risks of HIV/AIDS and other psychosocial problems. In some parts of Nigeria, boys and girls do not have equal access to education. In some instances girls are forced to get married while their brothers go to school. There is male preference in the employment of workers and the consideration is usually not based on competence. Women police officers require official permission to marry while men do not. Pregnant women are not admitted to schools of nursing as a policy. In some parts of Nigeria, pregnant women are denied nutritious food such as snail, meat and eggs. They present to hospital only with the permission of their husband. It has been shown that the continuing prevalence of these harmful traditional practices and the low status of women contribute to the increasing rate of maternal death in Nigeria, which ranks among the highest in the world. ${ }^{22}$

\section{The way forward}

In spite of the health consequences, women are still reluctant to disclose causes of violence; instead they would rather suffer in silence. Since the United Nations Declaration on the Elimination of Violence Against Women, ${ }^{23}$ no concrete attempt has been made to address the issue. Preventing VAW should therefore be revitalised and promoted as an important reproductive health intervention to address the debasement of women. There is a need for public enlightenment on what constitutes VAW. Education on the reproductive and sexual rights of women should be intensified by means of print and electronic media and women's organisations. There is also an urgent need to review cultural and traditional laws that negate women's rights - to economic emancipation, to autonomy, to education and to matters relating to their reproductive 
system. Presently in Nigeria, VAW by male partners is widely condoned, as the belief that a husband may chastise his wife by beating her is deeply embedded in the culture. ${ }^{2,9,10}$ Repealing of such cultural laws will improve women's health and status.

Also, VAW should be recognised as a criminal issue through the amendment of existing legal instruments and domestication of international laws and treaties on VAW to which Nigeria is a major signatory. VAW should not be restricted to being a husband and wife issue; rather it should be made a state affair and laws should be made to allow law enforcement agents to intervene in domestic quarrels between couples.

In addition, the empowerment of women's sociocultural organisations can accelerate the abolition of all forms of violence. Women can play effective roles in eliminating gender-based violence and in initiating and implementing programmes that guarantee their reproductive and human rights. A women's group in Anambra State, Southeast Nigeria has successfully eliminated widowhood practices in the area. ${ }^{24}$ Women's groups should therefore be mobilised, strengthened and encouraged to champion issues that affect their well-being.

Training programmes to raise awareness, build strong advocacy, and generate interest in issues related to women should be organised regularly. There is also the need to train health professionals about gender-based issues. Apart from being instruments of positive change in the society, health care providers should assist in alleviating the sufferings of women exposed to domestic violence through physical support, medical treatment, counselling and prompt referral to other social agencies where assistance can be offered. Timely management and referral can interrupt the cycle of violence, prevent further injury and initiate the help-seeking process. A significant proportion of health workers in our environment lack the knowledge and experience required to suspect and recognise VAW. ${ }^{25}$ Efforts should therefore be made to incorporate topics related to domestic violence and the sexual and reproductive rights of women into the curriculum of doctors, nurses and students in higher education institutions.

\section{Conclusions}

In conclusion, preventing VAW should be given the highest priority in Nigeria where culture, tradition, customs, religion and patriarchy all combine to nurture reproductive ill-health and debasement of the status of women in the society. Elimination of harmful cultural practices and legislation to prohibit VAW and enforce the sexual and reproductive rights of women are areas that need urgent attention. Education and enlightenment of the populace must be intensified in order to engender attitudinal changes. Finally, improvement in the reproductive health and rights of Nigerian women will speed up progress towards achieving the targets of the Millennium Development Goals.

Statements on funding and competing interests

Funding None identified.

Competing interests None identified.

\section{References}

1 Ogbuji C. Violence against women: impact on their reproductive health. Trop J Obstet Gynaecol 2004; 21: 61-64.
2 Okemgbo CN, Omideyi AK, Odimegu CO. Prevalence, patterns and correlates of domestic violence in selected Igbo communities in Imo State, Nigeria. Afr J Reprod Health 2002; 6: $101-114$

3 Bacchus LJ, Bewley S, Mezey G. Domestic violence and pregnancy. Obstet Gynecol 2001; 3: 56-59.

4 World Health Organization (WHO). Violence Against Women, Women's Health and Development, Family and Reproductive Health. WHO Consultation. Geneva, Switzerland: WHO, 1996.

5 Heise L, Pitanguy J, Germain A. Violence Against Women: The Hidden Health Burden. World Bank Discussion Paper, No. 255. Washington, DC: World Bank, 1994.

6 International Conference on Population and Development (ICPD 1994). Summary of the Programme of Action. United Nations Department of Public Information, DPI/1618/POP, March 1995. http://www.un.org/ecosocdev/geninfo/populatin/ icpd.htm [Accessed 12 July 2007].

7 United Nations (UN). The Beijing Declaration and the Platform for Action. Fourth World Conference for Women. Beijing, China, September 1995. UN Document DPI/1766/wom; 112-113. 1996. http://www.un.org/womenwatch/daw/beijing/ platform/ [Accessed 12 July 2007]

8 De Bruyn M. Violence related to pregnancy and abortion: a violation of human rights. Sex Health Exch 2002; 3: 14-15.

9 Odujirin O. Domestic violence among married women in Lagos. Int J Gynaecol Obstet 1993; 34: 361-366.

10 llika AL, Okonkwo PI, Adogu P. Intimate partner violence among women of childbearing age in a primary health care centre in Nigeria. Afr J Reprod Health 2002; 6: 53-58.

11 Fawole OI, Aderonmu AL, Fawole AO. Intimate partner abuse: wife beating among civil servants in Ibadan, Nigeria. Afr $J$ Reprod. Health 2005; 9: 54-64.

12 Fawole OI, Ajuwon AJ, Osungbade KO, Faweya CO. Prevalence and nature of violence to young female hawkers in motor parks in south western Nigeria. Health Educ Res 2003; 102: $230-238$.

13 Aimakhu CO, Olayemi O, Iwe CA, Oluyemi FA, Ojoko IE, Shoretire KA, et al. Current causes and management of violence against women in Nigeria. J Obstet Gynaecol 2004; 24: 58-63.

14 Wolfe DA, Jaffe P, Wilson S, Zak L. Children of battered women: the relation of child behaviour to family violence and maternal stress. J Consult Clin Psychol 1985; 53: 657-665.

15 Jewkes R. Intimate partner violence: causes and prevention. Lancet 2002; 359: 1423-1429.

16 Schoepf BF. Women, AIDS and the economic crisis in central Africa. Can J Afr Stud 1988; 22: 625-644.

17 Anochie IC, Ikpeme EE. Prevalence of sexual activity and outcome among female secondary school students in Portharcourt, Nigeria. Afr J Reprod Health 2001; 5: 63-67.

18 Ejikeme GG. Theories of sexual harassment. Society 1999; 4 : 46-49.

19 Ladipo OA. The Cairo Consensus and Millennium Development Goals: reality or mirage? Trop J Obstet Gynaecol 2005; 22: 89-99.

20 National Population Commission (NPC). Nigeria Demographic and Health Survey 1999. Abuja, Nigeria: NPC, 1999.

21 lbekwe PC. Physical and psychological sequelae of female genital mutilation: a case report. Niger J Med 2004; 13: 293-294.

22 High rate of maternal deaths in Nigeria is a cause for alarm. Communiqué from the 38th Annual Scientific Conference of the Society of Gynaecology and Obstetrics of Nigeria (SOGON), Makurdi, Benue State, Nigeria, November 2004. Trop J Obstet Gynaecol 2005; 22: 100.

23 United Nations (UN). United Nations Declaration on the Elimination of Violence Against Women. UN Document A/RES/48/104. 1993. http://www.un.org/documents/ga/res/48/ a48r104.htm [Accessed 12 July 2007].

24 Oyediran KA, Isiugo-Abanihe U. Perceptions of Nigerian women on domestic violence: evidence from 2003 National Demographic and Health Survey. Afr J Reprod Health 2005; 9: 38-53.

25 National Population Commission (NPC) and ORC Macro. Nigeria Demographic and Health Survey 2003. Calverton, MD: NPC and ORC Macro, 2004.

\section{Visit the Faculty Website at www.ffprhc.org.uk}

